\title{
Potential Role of Micro-Algae on Global Energy Supply
}

\section{Abstract}

The most effective ways to reduce $\mathrm{CO} 2$ emissions are to improve the energy efficiency of each economic sector and to reduce the cutting of tropical and temperate forests around the world. These options, however, may not fully reach their technical and economic potential due to various political and socioeconomic blocks. The most practical of these is to increase $\mathrm{CO} 2$ sinks through photosynthesis in both standing tree biomass and in ocean primary producers. The use of marine algae as $\mathrm{CO} 2$ sinks is for large-scale $\mathrm{CO} 2$ mitigation: the use of phytoplankton through Fe fertilization and macro algal (kelp) farms, which can be used for energy production.

The reduction of $\mathrm{CO} 2$-emissions that are damaging our climate is one of the major challenges of contemporary energy management. Nature itself offers us possibilities to produce energy $\mathrm{CO} 2$-neutral with the help of hydrogen producing micro-algae. Under certain conditions the light energy collected by photosynthesis is used to transfer electrons to hydrogen producing proteins called hydrogenases. Processes were recently developed that allow long-term production of hydrogen by micro-algae. Under sulphur deprivation the green alga adapts its metabolism from oxygen production and CO2-fixation towards hydrogen production. Therefore the biotechnological process is divided into the growth phase, the hydrogen production phase, and the resulting spent algae can be used for biomass production of fuel. Thus by control of growth conditions green algae can be used to produced hydrogen fuel, methane and a whole host of hydro carbons for fuel.

Our planet is $75 \%$ ocean; it seems only natural to look to the ocean as a source of energy and a source to help lower our atmospheric CO2. The most appropriate regions for this kind of production would not only be the continental shelf regions but also in the open ocean where iron fertilization is being utilized to help with algal blooms. Algae and kelp may not be the holy grail of green energy sources, but they are a viable resource to help in our energy and environmental crisis.

\section{In the news}

Source: The Marin Independent Journal by Jennifer Upshaw. Sage Callaway a Molecular Cell Biology major and San Rafael resident, will present research on reducing carbon dioxide emissions by using algae and kelp.

The work involves a fish tank full of algae. The tank, placed in a lab refrigerator, is topped with a plate with a hole and a tube to which a garbage bag is attached. The contraption enables researchers to measure the emissions captured in the bag and compare it with an identical tank set up on the roof of the science building

The effort appears promising, Callaway said.

"It seems like a pretty good source of fuel without cutting down rainforests," "We can do it," Callaway said of alternative fuel sources. "If little ole me in this little lab, if we can do it, the big boys can do it."

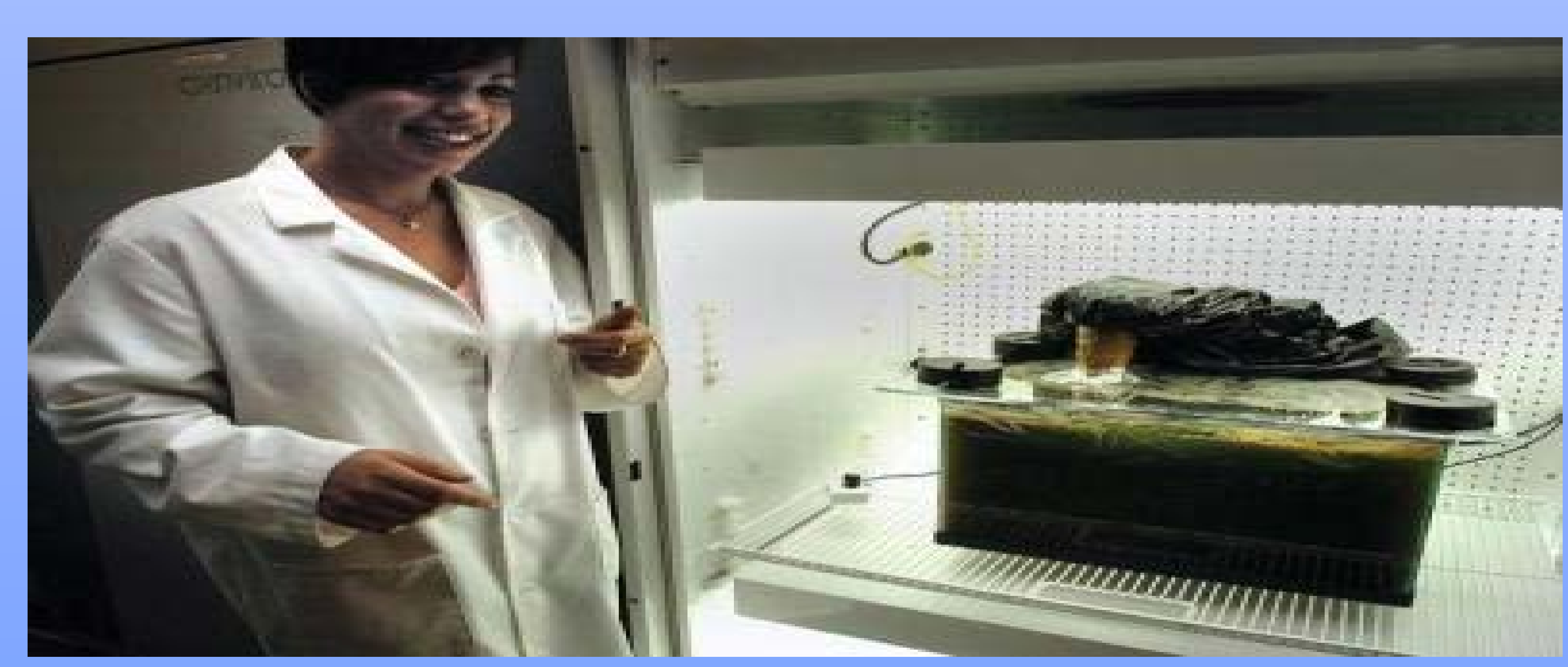

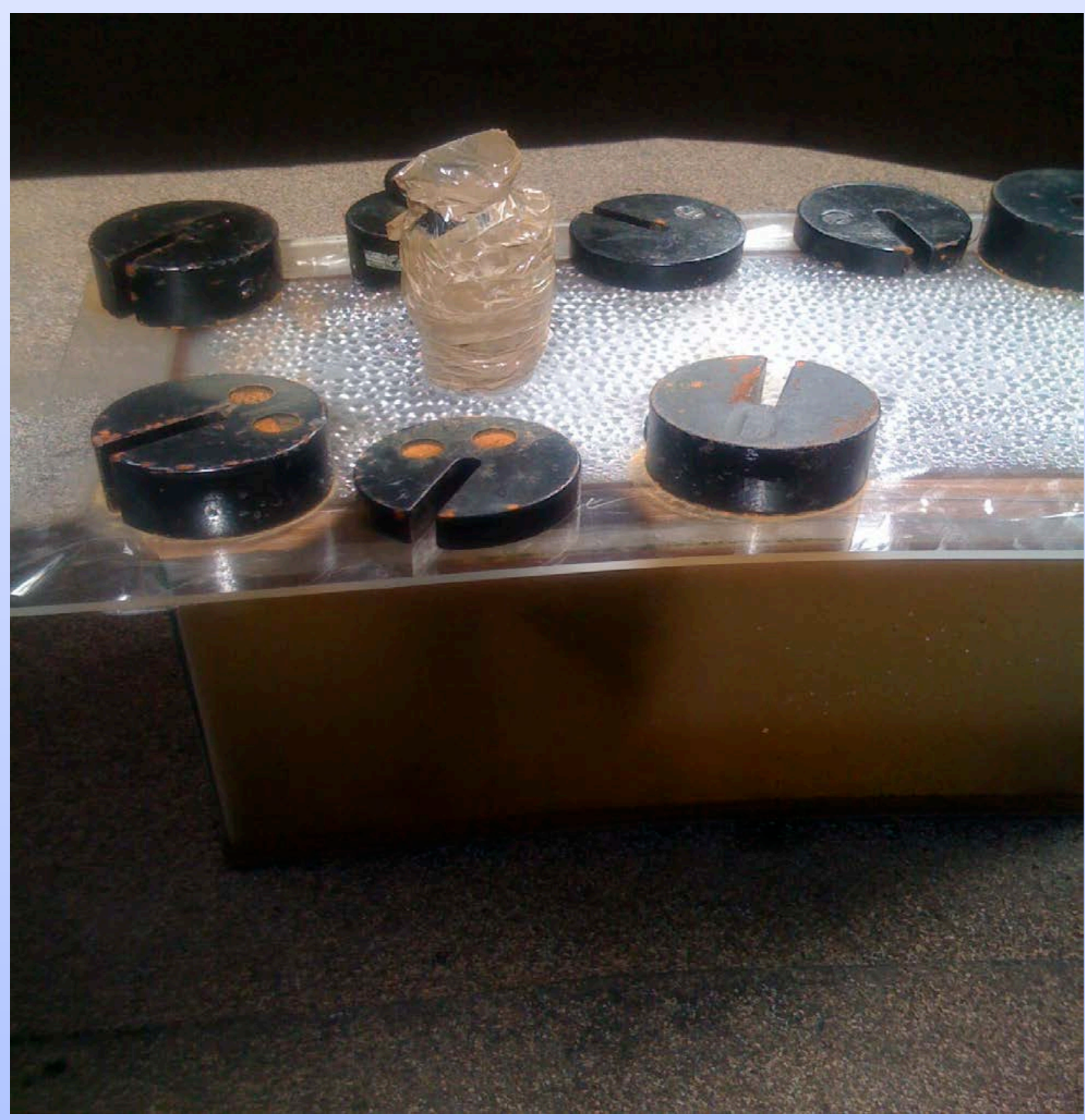
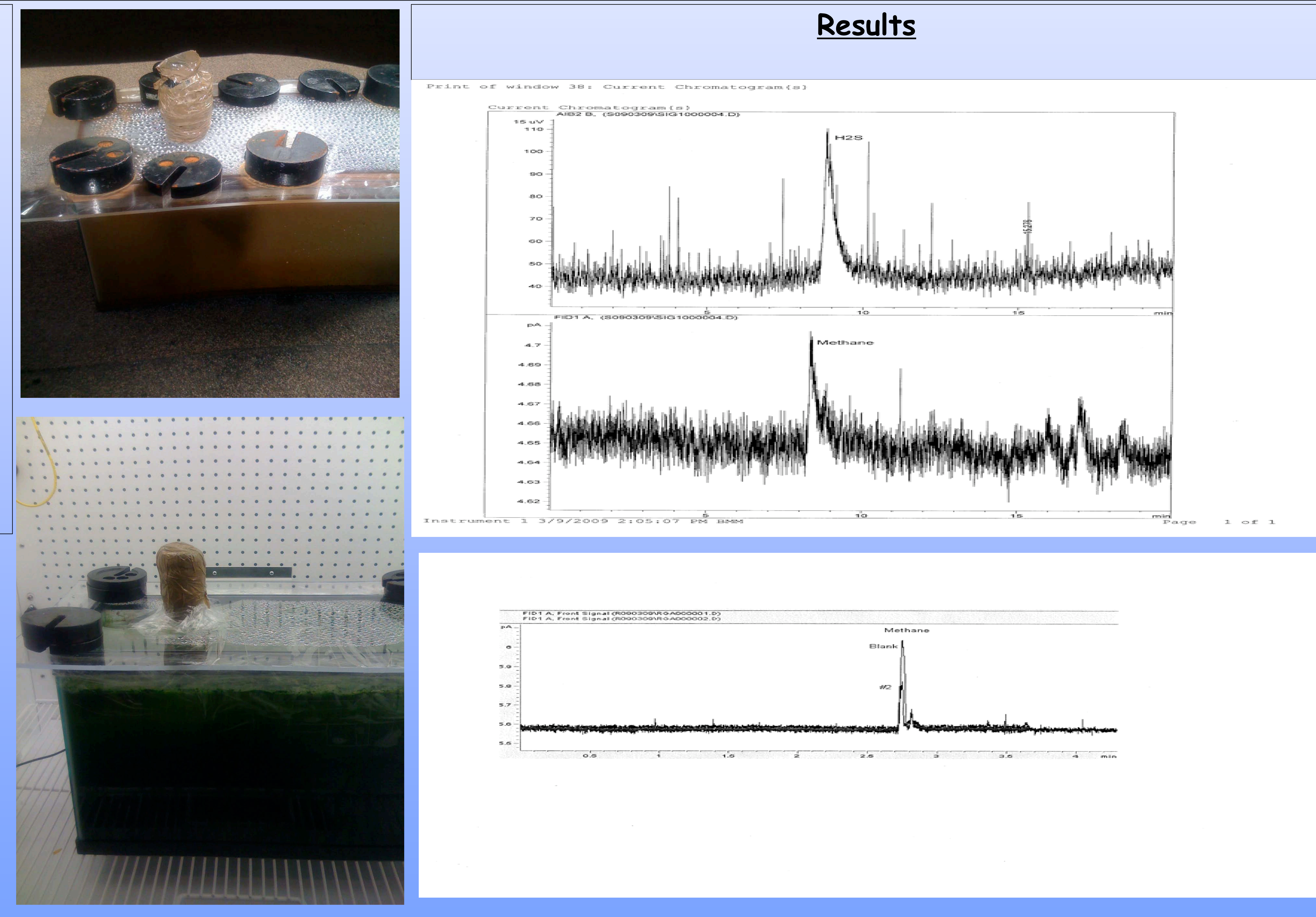

\section{Conclusion}

Overall, it appears that visitors to PORE are using time on the trails to think about their personal values. The results were statistically significant for the combined Bear Valley trail data and the Limantour Beach trail data. Other significant results for the combined Bear Valley trail and Limantour Beach trail were being close to nature and to experience solitude. Visitors were also using their time to be with people that enjoy doing the same things they liked to do. This was statistically significant for the combined trail data and Bear Valley trail. For Limantour Beach trail the results were significant for experiencing nature. This is not surprising considering the beauty of the beach. For Bear Valley trail the results were statistically significant for importance of physical health. It appears that the visitors walking or hiking this trail are doing so specifically for the exercise. The combined trail data was significant for visitors rating it important or very important to get away from the usual demands of life. 